\title{
Combining Multicriteria Decision Analysis and Cost-Benefit Analysis in the assessment of maritime projects financed by the European Investment Bank
}

Mark Brian Clintworh, Evangelos Boulougouris, and Byung Suk Lee University of Strathclyde Department of Naval Architecture, Ocean \& Marine Engineering

As the financing institution of the EU, the European Investment Bank (EIB) has a long history of investments in the maritime sector. The EIB's support for the sector is guided by EU maritime policy which is increasingly influenced by nonfinancial criteria such as safety, environment and employment. The increasing inclusion of non-financial criteria into financial decisions adds to the degree of subjectivity involved in project investment decisions, especially ones involving public funds. This subjectivity is present in individual decision maker's thought processes when assessing the relative importance of each criterion. Within this context, this paper examines a methodology which combines established financial analysis methods with multi criteria decision analysis (MCDA) in an effort to address this complex issue. The aim is to develop a model, which incorporates financial and non-financial criteria whilst accounting for the inherent subjectivity in investment decision making, in a transparent and auditable manner.

The paper examines the application of the model to a fleet expansion project which has been financed by the EIB. Further research is proposed including ways in which the model could also be utilised as a performance indictor to track the degree to which EIB financing meets the goals outlined in EU maritime policy.

Keywords: analytical hierarchy process (AHP); multi criteria decision analysis (MCDA); fuzzy AHP; European investment bank (EIB); project appraisal, cost benefit analysis (CBA); 


\section{INTRODUCTION}

This paper proposes a methodology to combine cost benefit analysis (CBA) and multi criteria decision making tools, using financial and non-financial criteria, to develop a heuristic model aimed at determining the extent to which individual EIB project investment decisions meet the goals of EU maritime policy whilst still maintaining essential financial integrity. The methodology proposed should adequately and transparently reflect both the quantitative (monetary and non-monetary aspects) and qualitative or subjective aspects of project assessment. These aspects are considered essential in providing a more accurate description of the total benefits both to the borrower and to society as a whole.

The EIB is mandated to implement EU policy in the maritime sector with a particular focus on port infrastructure, construction of new vessels, environmental retrofitting of vessels, coastal protection and research, development and innovation (RDI) and the protection of the environment and energy efficiency (European Commission 2012).

Prior to the granting of a loan, the EIB performs a lengthy legal, financial, economic, technical and environmental due diligence exercise which is termed project appraisal; its purpose is to justify the allocation of EIB funds for projects prepared by public and commercial project promoters. These are largely assessed in monetary terms, as investments are policy driven in pursuance of the financial and economic benefit to the EU. When assessing the financial and economic value of its investments, the EIB's current practice is to employ CBA tools; Net Present Value (NPV); Internal Rate of return (IRR); and Economic Rate of Return (ERR) as criteria. These tools are used to demonstrate financial evidence in monetary terms to support project finance. 
However, CBA tools alone are limited in their scope, as regards non-financial elements, as well as in accounting for subjectivity of human decision making. Firstly, policy choices are rarely between a simple choice of whether or not to implement a project, as there are generally several viable alternatives to the proposed project, e.g. the construction of a new green field port or upgrading an existing port. In some maritime projects, identifying and quantifying the project's financial benefit through CBA is not the sole aim, as the overall goal might be the provision of an essential service. The fact that CBA tools alone can only account for a weighted mixture of financial evidence inhibits its effectiveness, as the decision to invest is affected by considerations that are not purely financial. This is evident in the likes of remote island ferry services and coastal and environmental protection, as well as projects proposed due to regulatory constraints (ballast water treatment systems or emission control areas) where returns measured in purely monetary values are obviously insufficient. Furthermore, national policy regularly demands the maintenance of a minimum of public service obligations. In these circumstances, project appraisal focuses on whether the project represents the most efficient method of providing the required service.

Secondly, investment decision making, especially involving the use of public funds, involves a degree of subjectivity in weighing the individual decision criteria. In project assessment, determining the importance of weights, for the expert assessments of the criteria, is an essential process. Furthermore, weighing the criteria involves human judgment which by nature is imprecise and vague. Within this context the MCDA methodology of fuzzy Analytic Hierarchy Process (F-AHP) has been often been considered as an effective method in accounting for such imprecisions.

Within this context, this paper proposes a methodology to quantify and include the more qualitative and non-monetary aspects involved in investment decisions, using a 
combination of CBA and F-AHP.

Finally, the paper develops a test case based on a vessel acquisition project which the EIB has previously financed. The case first identifies a limited number of alternatives to this real project, devised to potentially meet the investment objectives targeted by the original proposal. The goal of the exercise was to ascertain through the model the degree to which each of the objectives aligned with EU maritime policy with a view to identifying the one which most closely matched the criteria.

\section{LITERATURE REVIEW}

By applying a weighting of project appraisal parameters, both qualitative and quantitative, an important recognition is made of the more subjective aspects of human behaviour. The Bank, as an EU institution, is deeply embedded in a complex multinational political context and as such there is a need to examine ways in which to address the subjectivity involved in international project appraisal. Experimental economics and behavioural decision/organization theory, point to the failure of rational choice as a model describing human behaviour (Jones, B.D. 1999). However, this does not mean that 'political decisions' are irrational. 'Bounded rationality' asserts that decision makers are intentionally rational (Jones, B.D. 1999); in other words, they are goal oriented and adaptive. However, due to the nature of human cognitive and emotional being, they occasionally err, when making decisions. Rational analysis in institutional contexts such as that of the EIB can help the decision making process by taking account of the above. Any chosen methodology needs to adequately reflect this subjectivity clearly and transparently.

There is an array of methods available for solving MCDA problems and one of the most widely accepted is the Analytic Hierarchy Process (AHP), developed by Saaty 
(1980). AHP allows the incorporation of judgments on both tangible and intangible data. The approach is centred on the structuring of pair-wise comparison matrices in order to evaluate both decision criteria and alternatives. This enables the establishment of a hierarchy which results in ranking the available alternatives open to decision makers.

Despite AHP's widespread use in academic, commercial and political spheres, the methodology does have its limitations. These include: AHP's inability of identifying incomparability when two incomparable elements are judged and; its compensatory nature, namely the fact that poor scores in one factor can be compensated by higher scores in another. Thus an option which does not fulfil the requirements in a specific attribute can still end up ranked as a better option. The method applied in this paper is also subject to these shortcomings, of which suitable account must be taken.

Furthermore, the AHP is open to criticism for its shortcomings in the treatment of the uncertainty inherent in the subjectivity involved in the mapping of human perceptions to exact numbers (Deng 1999). In short, pure AHP may not fully reflect human behaviour, as decision makers usually feel more at ease with submitting interval judgments rather than crisp single natural or whole numbers. When a project appraiser is faced with selecting pairwise comparisons in standard AHP, they may not consider it appropriate to assign single numerical values due to uncertain and insufficient data. As a result of concerns with data derived from human subjectivity, the fuzzy set theory, developed by (Zadeh 1965), can further assist in decision making. One of the methods used to address this limitation is the embedment of fuzzy theory to basic AHP. This approach is known as Fuzzy AHP (F-AHP). One of the earliest examples of combining classical AHP with fuzzy set theory was considered (van Laarhoven and Pedrycz 1983). 
The biggest challenge with F-AHP is related to acquiring a normal and convex fuzzy number. The method also requires cumbersome calculations. Buckley (1985) utilises the geometrical mean method in deriving fuzzy values, whereas Chang (1992) introduces an approach involving 'triangular fuzzy number usage and extent analysis method for synthetic extent values of pair-wise comparisons'.

Examples of the application of F-AHP can be found in the assessment of water management plans; critical decisions in new product development; flexible manufacturing systems and safety management in production; selection of enterprise resource planning systems; evaluation of success factors in e-commerce; personnel management.

With the above in mind and taking suitable account of weaknesses, this paper proposes an F-AHP based MCDA methodology combined with CBA tools. Leviakangas and Lahesmaa (2002) use the CBA for various projects as criteria in the AHP hierarchy to evaluate the most appropriate intelligent transport system (ITS). Mahmoodzadeh et al (2007) propose a method for project selection using F-AHP, CBA \& TOPSIS. Babic and Tomic-Plasibatalso (1999) incorporate CBA tools as criteria in evaluating investment projects. Haven (1998) utilises a fuzzy extension of the AHP in order to rank various equal NPV projects by utilising the NPV as criterion in the AHP hierarchy. Project selection questions have been addressed in various management forums, examples of which are Research \& Development (Loch and Kavadias, 2002); Environmental Management (Ramcharan and Dey, 2005); and Quality Management (Hariharan et al. 2004).

With regards to MCDA application in the maritime sector, the literature is abound with material relating to the application of AHP to navigation, safety, route and port selection and even supplier selection, to name but a few. However, little material is 
found on investment decision making in the maritime sector. One such article is from Rousos and Lee (2012) which examines widening the traditional perspective through which shipping investment decisions are made by applying AHP for the quantification of qualitative decision processes with CBA tools.

\section{RESEARCH METHODOLOGY}

An integrated F-AHP-CBA model is one that sets CBA output as a sub-set of the model criteria in the F-AHP hierarchy. The remaining criteria will comprise non-financial elements. This integrated approach is frequently found in the literature and has found recognition in the academic world as an acceptable and efficient multi-criteria methodology.

$C B A$

CBA is the standard economic appraisal technique used by the EIB to assess the socio-economic desirability of a project. Its use is intended to result in a number of quantitative project metrics, which are then corrected for various distortions (price etc.) and market constraints. These metrics are the ERR and the Economic Net Present Value (ENPV). A project's ERR is essentially an assessment of the average annual return to EU/society on the capital invested throughout the lifetime of the project. It represents the interest rate at which the project's discounted costs and benefits are in equilibrium. A project is viewed as acceptable by the EIB if the ERR meets or exceeds the social discount rate. A project's ENPV is the difference between discounted costs and benefits at a given discount rate. Projects generally must have a positive ENPV in order to qualify for Bank support. CBA represents more than a simple set of indicators. CBA analysis can assist in clarifying: 
- project goals.

- project stakeholders as well as the effects on those stakeholders.

- overall impact on government finance.

- the project's financial sustainability.

- project risks.

Moreover, CBA helps estimate the results of a project if implemented, and likewise if the project is not implemented. It assists in evaluating whether the project meets the stated goals, and in indicating if the project components are the most efficient in achieving those goals. In short, CBA is an integral part of the work presented in this paper by providing metrics which enable comparison between project alternatives.

With some projects a suitably comprehensive CBA operation is not possible. In these cases, the due diligence aim is to enhance CBA and replace it with a cost effectiveness analysis (CEA), particularly where the investment decision is taken within a socio-political context. In sectors where project benefits are difficult to measure, through the use of CBA/CEA, the Bank has implemented MCDA as an appraisal technique. In particular, the Bank has used MCDA in assessing investments in urban development as well as in health and education. In these sectors, costs are relatively straightforward to appraise, however, the benefits are not immediately manifested in financial terms. It is in these circumstances MCDA methods have demonstrated their value in the assessment of the nonfinancial and subjective elements of decision making. Furthermore, combined with elements of CBA, it can provide a balanced indicator in the assessment of socio-economic benefits.

In general, the suitability of the above appraisal techniques is summarised in Table 1. The two drivers are the extent to which the output variables can be monetised, and the degree to which the project produces multiple outputs (EIB 2008). 
$F-A H P$

F-AHP is mainly characterised by the classification of values which do not have sharply defined boundaries. Subjective judgments can be represented by fuzzy numbers. This paper proposes the use of triangular fuzzy numbers defined by three real numbers, expressed as $(l, m, u)$. Triangular fuzzy numbers are represented as shown in Figure 1:

\section{Figure 1}

$$
\mu_{A}(x)=\left\{\begin{array}{cc}
(x-l) /(m-l) & l \leq x \leq m \\
(u-x) /(u-m) & m \leq x \leq u \\
0 & \text { otherwise }
\end{array}\right.
$$

The Buckley (1985) method is adopted here, to determine the relative weights for criteria and alternatives. The steps of the procedure are as follows:

In order to compare the criteria and hence complete the questionnaire, the expert appraisal team will utilise Table 2 to guide their judgements.

\section{Table 2}

The pairwise comparisons rely on the judgements of experts to formulate priority scales. These measure the intangibles in relative terms. The comparisons are made using a scale of absolute judgements that denote the degree to which one criterion dominates another with respect to a given attribute.

The pair wise contribution matrix is shown in Eq.1, where $\widetilde{d_{l j}^{k}}$ indicates the $k^{t h}$ decision maker's preference of $i^{\text {th }}$ criterion over $j^{\text {th }}$ criterion, via fuzzy triangular numbers. Here, a tilde represents the triangular number demonstration, for example, 
$\widetilde{d_{12}^{1}}$ represents the first decision maker's preference of first criterion over second criterion, and equals, $\widetilde{d_{12}^{1}}=(2,3,4)$.

$$
\widetilde{A^{k}}=\left[\begin{array}{cccc}
\widetilde{d_{11}^{k}} & \widetilde{d_{12}^{k}} & \ldots & \widetilde{d_{1 n}^{k}} \\
\widetilde{d_{21}^{k}} & \ldots & \ldots & \widetilde{d}_{21}^{k} \\
\ldots & \ldots & \ldots & \ldots \\
\widetilde{d_{n 1}^{k}} & \widetilde{d_{n 2}^{k}} & \ldots & \widetilde{d_{n n}^{k}}
\end{array}\right]
$$

N.B. more than one decision maker requires an average,

$$
\tilde{d}_{i j}=\frac{\sum_{k=1}^{k} \widetilde{d_{l j}^{k}}}{K}
$$

Applying average preferences, pairwise contribution matrices are as follows,

$$
\tilde{A}=\left[\begin{array}{ccc}
\tilde{d}_{11} & \ldots & \tilde{d}_{1 n} \\
\ldots & \ldots & \tilde{d}_{n n}
\end{array}\right]
$$

The calculation of the geometric mean of fuzzy comparison values for each comparison values for criterion $\left(\tilde{r}_{i}\right.$ represents triangular values) is:

$$
\tilde{r}_{i}=\left(\prod_{j=1}^{n} \tilde{d}_{i j}\right)^{1 / n}, i=1,2, \ldots . n
$$

For fuzzy weights criterion first calculate the vector summation of each $\tilde{r}_{i}$ and then multiply with the reverse vector,

$$
\widetilde{w}_{i}=\tilde{r}_{i} \otimes\left(\tilde{r}_{1} \oplus \tilde{r}_{2} \oplus \ldots \ldots \ldots \tilde{r}_{n}\right)^{-1}=\left(l w_{i}, m w_{i}, u w_{i}\right)
$$

As $\widetilde{w}_{i}$ are triangular fuzzy numbers they require 'defuzzification' using the Centre of Area method,

$$
M_{i}=\left(l w_{i}, m w_{i}, u w_{i}\right) / 3
$$


As $M_{i}$ is a non fuzzy number it required normalisation as follows,

$$
N_{i}=M_{i} / \sum_{i=1}^{n} M_{i}
$$

The operations described above are then performed to establish the normalized weights of criteria and the alternatives. By multiplying each alternative weight with related criteria, the scores for each alternative are calculated. The rankings are then presented to the Bank's management for decision.

\section{Alternatives}

The alternatives, $\mathrm{A}$, of the model will be a finite set of maritime investment projects which all have the same goal as the project presented to the EIB for funding, where $A=\{A i \forall 1,2,3 . . M)$. The model outputs will be the ranking of the project alternatives based on selected criteria, $\mathrm{G}$ where $G=\{G i \forall 1,2,3 \ldots N)$

The formula for establishing alternatives and criteria for the methodology is guided by EU/EIB strategies and objectives, formally termed the project eligibility.

Once a prospective borrower submits their project to the Bank, before beginning to fully appraise that project, the Bank's services must be satisfied that the project is eligible. The current EIB eligibilities are listed in Figure 2: Primary Corporate Operations Plan (COP) objectives, and the Transversal Objectives.

\section{Figure 2}

It is within the context of the above eligibilities that the project alternatives will be chosen. Each alternative should match one or more objectives. However, all alternatives should match the same objectives.

The alternatives should be realistically identified and scoped and effort should be directed at quantifying the key metrics. It is accepted that some of the projects' 
qualities or issues can only be described qualitatively. Examples of such metrics include:

- Projected results

- Flexibility

- Employment consequences

- Financial impact

- Third party consequences

- Workload, performance, capacity objectives

- Ease of accessibility

- Physical characteristics

- infrastructure implications

- Project planning

\section{Criteria}

Criteria are used to evaluate the project alternatives which have been identified through the process outlined above. These criteria include financial and non-financial elements specific to the nature of the investment concerned.

The model presented in this paper comprises two levels of criteria in a four level hierarchy shown in Figure 3. The second level in the hierarchy is divided into two major factors in project assessment, financial and non-financial criteria. It should be noted here that the second level is for illustrative purposes. Further granularity is added by the inclusion of sub-criteria to the respective factors at level 3. The fourth level represents the set of proposed project alternatives.

Figure 3 
The chosen number of criteria will, to a large extent, reflect the nature of the project as well as the quality and level of project information. Attention should be given to achieving an appropriate and effective level of criteria, entailing a manageable level of analytical effort which, in turn, delivers an acceptable level of transparency. Likewise, there is potential that important aspects, positive or negative, may be unaccounted for if insufficient criteria are identified. Potentially redundant/duplicate criteria, or criteria which do not assist in differentiating alternatives should be filtered. The quantifiable financial sub-criteria have been chosen based on the EIB's emphasis on the CBA metrics of IRR, NPV, ERR and project cost. NPV and IRR are the two most common parameters used to compare investment projects. It is important to note that whilst these two metrics are strongly correlated, they provide two differing metrics, absolute value and percentage, commonly used in investment decisions. However, in a certain projects, the two criteria may give contradictory results, i.e. one project is acceptable if we consider the NPV method, but at the same time IRR method favours another project. The reasons of conflict between the two are due to the variance in the inflows, outflows, and life of the project. In these cases IRR is considered to be inappropriate. The ERR is an important factor in selecting projects, based on their value to society as a whole; EIB, as a policy driven Bank, considers this as essential to the decision making process. The fourth financial criterion is the initial cost of investment; obviously an essential metric in the process. This is especially the case for public investments which allocate tax revenue and where little or no monetary returns can be expected.

It should be noted at this stage that market risk is also incorporated into the project's financial output, through the use of the capital-asset pricing model (CAPM). 
An adjusted risk premium is applied to forecast project returns and costs, corresponding to the projected volatility. The result is a project NPV reflecting its risk weighted value.

The second set at level 2 comprises the non-financial sub-criteria which have been determined as essential. These elements are both qualitative and quantitative metrics. Environment and employment are two key cores in EU policy. For the purposes of brevity in this pre-appraisal model, environmental criteria also include climate change considerations which will ultimately be the subject of a full review during the final due diligence exercise. Employment will consider both the temporary employment, generated during the project's implementation, in addition to full time equivalent positions, created or lost as a result of the project's implementation. Account must also be taken of indirect employment effects generated by the project but which are difficult to quantify (suppliers, services etc.). The EU policy objectives criterion will be a metric which indicates the extent to which project eligibility is met by each alternative. Finally, the technological fit criterion is chosen as a gauge of the extent to which the technical aspects of the proposed alternative are considered adequate in meeting the overall goals of the initial project.

\section{Criteria - Pairwise Comparisons}

Applying fuzzy set theory to AHP qualitative judgments can make comparison more intuitive, reduce assessment bias, and improve the treatment of subjectivity in pairwise comparisons. Wherever feasible, this approach adopts quantitative assessment of alternatives with respect to the criteria.

Quantitative inputs are a critical block of the comparisons, as this inserts a dynamic element in the proposed model which is able to distinguish between project proposals and time. The inputs to the model represent the actual numbers to be normalised so as to obtain the decision matrices. 
These inputs are: the NPV, IRR and the ERR of each alternative; the alternatives' Project Costs (PC) and the employment generated. Four of these inputs are sought to be maximised, namely the NPV, IRR and ERR and employment generated. The fifth one, that is Project Costs, is sought to be minimised.

The decision matrix $\mathrm{B}_{\mathrm{i}}, i \in(\mathrm{NPV}, \mathrm{IRR}, \mathrm{ERR}, \mathrm{PC}$, Employment, Environment), requires maximising and is derived directly by normalising the input vector, $\mathrm{A}_{\mathrm{i}}, i \in$ (NPV, IRR, ERR, PC, Employment, Environment). For example, the decision matrix of the IRR input is obtained by a one-to-one correspondence of the input IRR matrix cells with the sought decision matrix cells $b_{j}$ so that:

$$
B_{I R R}=\left[b_{1}, \ldots, b_{6}\right]^{T}: b_{j}=a_{n}\left(\sum_{1}^{8} a_{i}\right)^{-1}, \forall \mathrm{j}, \mathrm{n} \in(1, \ldots, 8)
$$

The matrix for the PC requires the inverse input vector cells followed by normalisation such that:

$$
B_{P C}=\left[b_{1}, \ldots, b_{6}\right]^{T}: b_{j}=a_{n}^{-1}\left(\sum_{1}^{8} a_{i}\right), \forall \mathrm{j}, \mathrm{n} \in(1, \ldots, 8)
$$

The non-financial and more qualitative comparisons are environment, employment and EU/EIB Priority Objective Eligibility. The values attributed to these criteria are determined by the COP Targets and eligibilities for the specific project and will be subject to future study. For the purposes of this paper the following approach is used:

- Environment: Simple \% reductions in $\mathrm{CO} 2, \mathrm{NOx}, \mathrm{SOx}$ and particulates gathered from data provided by the borrower and manufacture of project components (or Classification Society). 
- Employment: Man-years of employment during construction and project operation.

- Technical Fit: Estimated by the Bank's project appraisal team from a range of 1-10, based on the technical aspects of the project's ability to reach the full COP target and Eligibility.

- Eligibility: Estimated by the Bank's appraisal team and selected from a range of 1-10, and based on the value added contribution of the Bank's involvement in the project.

\section{Criteria decision vectors - Establishing the decision matrix and the questionnaire}

The first step in applying our model will be a review of the initial project proposal submitted to the Bank in order to determine whether the proposal is in line with EU/EIB policy. This review will be based on the eligibilities described above. If the proposal is deemed eligible then a limited set of alternatives will be determined, utilising a set of similar eligibilities and project goals to the initial project proposal submitted. According to the alternatives identified, the set of criteria will be established in order to construct the pairwise comparison matrix.

The derivation of the pairwise comparison matrix depends on expert judgements to determine the criteria set, and derive their priority scales. For this exercise a number of senior engineers and economists, with extensive experience in the appraisal of large shipping and port infrastructure projects, were instrumental in the identification and development of the test criteria set and the derivation of the questionnaire.

The comparison of the various criteria by their preference is a clearly 
subjective phase, meaning that preferences may vary depending on various externalities. However, 'subjectivity' is something that requires serious consideration in the Bank's commercial and socio-political context, as it represents delicate realities in a significant number of cases. The goal here is not to eliminate subjectivity from the investment evaluation process but to attempt to account for it, since it is an inherent part of the evaluation process.

The procedure used to establish the relationships follows the F-AHP procedure and proposes that these comparisons are established on the basis of a questionnaire comparing the various sub-criteria of level two between each other. In the Bank's case, it is proposed that this questionnaire be the subject of more rigorous research in order to evaluate to what extent its final compilation can be the result of a more automated procedure. A completed questionnaire can be found in Figure 4. The appraisal officer's preferences towards the criteria are transformed in a numerical value using the scale described in Table 2.

After all pairwise comparisons have been established, the preference vector is calculated.

\section{CASE STUDY}

This section describes the application of the model to a project previously completed by the Bank. The case concerns commercial vessel new builds which is typical of the type of vessel acquisition projects for which the Bank provides funding.

The test case project consists of the construction of six ro-ro / multi-purpose cargo vessels. The vessels would be employed within the borrowers' existing Northern Europe - West Africa routes. The project aimed to replace nine older vessels of the 
borrower's fleet which were operating in these routes and should therefore introduce increased fuel efficiencies and reduce overall harmful emissions on these routes. The vessel high level specifications are:

- Length overall $236.30 \mathrm{~m}$

- Moulded breadth $36.16 \mathrm{~m}$

- Deadweight 31,607 dwt

- Gross tonnage 71,600

- Main engine Hyundai - Wartsila RT-Flex 58T-E: MCR 17.4 MW

- Service Speed 20.2 knots

All six vessels and equipment will be constructed to the requirements of a European flag and under survey by a classification society, member of IACS (International Association of Classification Societies).

The aim of the project is essentially an increase in fleet capacity, together with an overall increase in energy efficiency. The project is forecast to generate high ERR, estimated at about $13 \%$. Returns are expected to be largely generated by operational costs savings, due mainly to fuel savings and charter costs (some currently wet chartered-in vessels will be released). Fuel consumption and related $\mathrm{CO}_{2}$ emissions are expected to be reduced by $28 \%$ in the project scenario versus the baseline scenario.

The 'expert' opinion is that the major weighting factor when considering the questionnaire and pairwise comparisons will be eligibility, as the project is expected to promote more fuel efficiency and thus contribute to sustainable sea transport. The project would therefore be eligible under EU Commission Directives and the following COP priorities: Protection of the environment and sustainable communities (sustainable inter-urban transport). The project is also consistent with the EIB Transport Lending 
Policy (EIB 2012) and contributes towards the EIB Climate Change transversal indicator (Mitigation - Sustainable Transport) (EIB 2012)

Following the identification of a valid set of initial project eligibilities, credible model alternatives were developed. The team of experts concluded that the following projects should constitute the set of model alternatives:

- New build - the borrower's project proposal

- Second Hand acquisition \& re-engine

- Lengthening and re-engine current vessels

The values for the relevant technical and economic metrics for two alternatives to the borrowers' project were subsequently estimated by the expert team, e.g. cargo capacity, energy efficiency and emissions, investment cost, financial returns. The goal of both alternatives was to provide equal or improved economic and social performance to that of the original project.

\section{DISCUSSION OF RESULTS}

The aim of the test case exercise, in terms of producing a final ranking, is to provide an indicator as to whether or not the proposed project, in the form in which it was presented to the Bank, was indeed the best option available to meet the intended goals and EU/Society's needs.

The method proposed is fundamentally based on the outcome of the questionnaire, the output of which was used to derive the (triangular number) pairwise comparison matrix. The questionnaire is shown in figure 4 and it was devised and completed as a result of feedback from the panel of experts described earlier. The results of the criteria comparisons showed a clear preference for ERR and for the more non-financial criteria, over the financial aspects of the project (investment cost, NPV or 
IRR). This reflects the emphasis on the social/employment and environmental aspects over commercial profitability, and that, indeed, the project experts viewed the project eligibility as one of sustainable transport.

\section{Figure 4}

The pairwise comparison matrix was used to derive Table 3, containing the set of geometric means of the fuzzy comparison values $\tilde{r}_{i}$ (eq. 4) from which the fuzzy weights , $\widetilde{w}_{i}$ (eq. 5) were derived. $\widetilde{w}_{i}$ were subsequently "defuzzified" to provide $M_{i}$ which was normalised to produce $N_{i}$, the final weighting fuzzy decision criteria preference vector:

\section{Table 3}

Tables 4 and 5 contain the numerical inputs for both the financial and nonfinancial criteria

\section{Table 4}

\section{Table 5}

These matrices are then normalised to compile the joint alternatives performance decision matrix in table 6:

\section{Table 6}

Finally, the integrated CBA/F-AHP results can be seen in Table 8.

\section{Table 8}

The data indicates that had the decision been based solely on the financial metrics of PC, NPV, IRR and ERR, the new build project would most likely be selected. But subjecting these metrics to further scrutiny, after comparing their relative importance through the questionnaire and F-AHP processing, the results produced a far closer ranking, suggesting that the introduction of further criteria would indeed assist in the decision making process. The inclusion of metrics representing employment, 
environment and technical fit and eligibility helped to provide a wider range of criteria on which to base any decision.

The Bank's decision to finance the new build project placed significant emphasis on the social and environmental aspects, whilst the financial returns still had to be satisfactory. However, unlike the methodology proposed in this paper, that decision was taken on a more formal quantitative assessment of the non-financial information at hand, whilst a full CBA was effected at the same time. In this respect, the results shown above seem to corroborate the decision to select the new build project, whilst being able to demonstrate clearly how non-financial criteria were accounted for.

Further effort is required to test the sensitivity of the model by further research on the design of the questionnaire, such that other scenarios are tested in more detail. Research is also needed into the rationale behind the 'expert choices' made in completing the questionnaire. As such, it is not possible at this stage to state with any conviction that the model, in its current form, clearly represents definitive solution which can be used in a real scenario.

Finally, there are some limitations to the model and some deficiencies that the proposed methodology could not overcome or avoid. The fact that it is based on the time value of money, requiring a certain number of assumptions and input data, puts some extra constraints on its value. In mitigation, the effects of potentially erratic CBA figures can be lessened by allowing the appraiser to assign less weight to these figures during the criteria 'preference' assignment.

The model chosen for analysis in this paper can and should be refined and restructured to fit the specific EIB and borrower needs. The options to create custom hierarchies are practically limitless. However, care must be taken to avoid 
overcomplicating assessments and to limit the criteria and alternatives such that the model doesn't lose the necessary transparency.

\section{CONCLUSIONS}

It is widely accepted that investment decisions, whilst being backed up by scientific reason, are also subject to individual emotions, intuition and are idiosyncratic in nature. It is essential that non-financial issues play an important role in public investment evaluation process and their influence on investment decisions be incorporated into formal decision making methodology.

It was in the above sense that this paper presented a methodology of combining CBA and F-AHP, using financial and non-financial criteria, to develop a heuristic model aimed at determining the extent to which individual project investment decisions meet both financial criteria and the goals of EU maritime policy. The methodology reflects both the quantitative (monetary and non-monetary aspects) and qualitative, or subjective, aspects of project assessment. These aspects are considered essential in providing an accurate description of the total benefits both to the borrower and to society by and large.

A case study, based on one of the Bank's past projects, involving a commercial fleet renewal, was presented to illustrate the use of the proposed model. The results indicate the capability and effectiveness of the model, which can assist the Bank's project appraisers to better evaluate realistic investment alternatives in terms of their fit to overall EU maritime objectives. The results of the case study demonstrate that, through fuzzy quantification, qualitative criteria can be incorporated into the investment decision process in a transparent and auditable manner. The case study exercise also demonstrated the necessity for closer coordination of expert opinion formulation. Criteria weightings, as well as option scoring, represent, respectively, opinions about 
the relative importance of the selected criteria, and the benefits that will be enjoyed from the implementation of each alternative. Whilst every attempt should be made to ensure that the method is transparent and methodical, it is important that the use of the model and the formulation of alternatives, criteria and the questionnaire are undertaken by a small expert appraisal team (as opposed to individual analysts) and that the results of the application are subjected to thorough sensitivity analysis.

In short, the model demonstrates a holistic approach to the problem studied and can constitute as a basis for further research and enhancement of maritime investment processes.

\section{Further research}

The use of the proposed model is of course not restricted to a fleet expansion case. Also, the selected criteria and alternatives may differ from those represented in the case study, or may comprise different alternatives and hierarchies and indeed consider the problem in more depth. The model may be applied to wider and more diverse areas of maritime project investment decisions. Furthermore, investment decisions are not limited to selecting between concrete projects. Alternatives could also represent other considerations, probabilities and possibilities concerning opportunities versus risks. Consider the following situation: the Greek government prioritise ferry service investments for remote island connections, deciding on levels of investment for individual island clusters. Fuzzy numbers could represent the amount of subsidies for the development of chosen routes. The government could then guarantee a certain interval of subsidies for the promotion of those routes. If, for example, the total grants would represent (the 'fuzzy' amount of) approximately 1 billion euros, the guaranteed interval of grants could be calculated. A prospective budget of between 0.8 and 1.5 
billion euros of subsidies could then be established. In this manner, future uncertainties could be more subtly accounted for than in the case of calculations based on crisp weightings.

Finally, further study should be undertaken in developing the model as the basis of a performance indictor that can used to track the degree to which EIB financing meets the goals outlined in EU maritime policy.

\section{Acknowledgements}

\section{Disclosure statement}

The authors have no conflicts of interest to declare.

\section{Funding}

N.A. 


\section{REFERENCES}

Babić, Z., and N. Tomić-Plazibat. 1999. "Making Investment Decisions with Multicriterial Analysis and Zero-One Programming, Management." Journal of Contemporary Management Issues 4 (1-2): 167-178.

Buckley, J. J. 1985. “Fuzzy Hierarchical Analysis.” Fuzzy Sets and Systems 17 (3): 233247. doi:10.1016/0165-0114(85)90090-9.

Chang, D. Y. 1992. "Extent Analysis and Synthetic Decision.”Optimization Techniques and Application 1 (1): 352-355.

Chou, S.-W., and Y.-C. Chang. 2008. "The Implementation Factors that Influence the ERP (Enterprise Resource Planning) Benefits.” Decision Support Systems 46 (1): 149-157. doi:10.1016/j.dss.2008.06.003.

European Commission. 2012. Strategic Goals and Recommendations for the EU's Maritime Transport Policy until 2020. European Union.

Deng, H. 1999. "Multicriteria Analysis with Fuzzy Pairwise Comparison.” International Journal of Approximate Reasoning 21 (3): 215-231. doi:10.1016/S0888613X(99)00025-0.

EIB (European Investment Bank). EIB Transport Lending Policy. 2011 Luxembourg: European Investment Bank.

EIB (European Investment Bank). 2008. The Economic Appraisal of Projects: An Overview of an Approach with the EIB. Luxembourg: European Investment Bank.

EIB (European Investment Bank). 2012. Methodologies for the Assessment of Project Ghg Emissions and Emission Variations. Luxembourg: European Investment Bank.

Hariharan, S., P. K. Dey, H. S. Moseley, A. Y. Kumar, and J. Gora. 2004. “A New Tool for Measurement of Process-Based Performance of Multispecialty Tertiary Care Hospitals." International Journal of Health Care Quality Assurance 17 (6): 302-312. doi:10.1108/09526860410557552.

Haven, E. E. 1998. "The Fuzzy Multicriteria Analysis Method: An Application on NPV Ranking." Intelligent Systems in Accounting, Finance \& Management 7 (4): 243-252. doi:10.1002/(SICI)1099-1174(199812)7:4<243::AIDISAF157>3.0.CO;2-F.

Jones, B. D. 1999. "Bounded Rationality.” Annual Review of Political Science. 
Leviäkangas, P., and J. Lähesmaa. 2002. "Profitability Evaluation of Intelligent Transport System Investments." Journal of Transportation Engineering 128 (3): 276-286. doi:10.1061/(ASCE)0733-947X(2002)128:3(276).

Loch, C. H., and S. Kavadias. 2002. "Dynamic Portfolio Selection of NPD Programs Using Marginal Returns.” Management Science 48 (10): 1227-1241. doi:10.1287/mnsc.48.10.1227.275.

Ramcharan, E. K., and P. K. Dey. 2005. "The Role of Environmental Factors in Industrial Site Selection Activities: A Case of Limestone Quarry Expansion in Barbados, West Indies." Impact Assessment and Project Appraisal 23 (2): 147154. doi:10.3152/147154605781765670.

Rousos, E.-P., and B. S. Lee. 2012. "Multicriteria Analysis in Shipping Investment Evaluation." Maritime Policy \& Management 39 (4): 423-442. doi:10.1080/03088839.2012.690080.

Mahmoodzadeh, S., J. Shahrabi, M. Pariazar, and M. S. Zaeri. 2007. "Project Selection by using Fuzzy AHP and TOPSIS Technique." World Academy of Science, Engineering and Technology

Saaty, T. L. 1980. The Analytic Hierarchy Process: Planning, Priority Setting, Resource Allocation. New York: McGraw Hill.

van Laarhoven, P. J. M., and W. Pedrycz. 1983. “A Fuzzy Extension of Saaty's Priority Theory." Fuzzy Sets and Systems 11 (1): 229-241..

Zadeh, L. A. 1965. "Fuzzy Sets." Information and Control 8 (3) 
Tables

Table 1. Suitability of methodologies across project circumstances.

Output Variables

\begin{tabular}{lccc}
\hline & & High & Low \\
\hline Quantifiable Variables & High & CBA/CEA & CBA/CEA \\
& Low & MCDA & CEA \\
& & & \\
\hline
\end{tabular}


Table 2. Linguistic terms and corresponding fuzzy numbers.

\begin{tabular}{lcc}
\hline Saaty & Definition & Fuzzy \\
Scale & Equally Important & Triangular Scale \\
\hline 1 & Weakly Important & $(1,1,1)$ \\
3 & Fairly Important & $(2,3,4)$ \\
5 & Strongly Important & $(4,5,6)$ \\
7 & Absolutely Important & $(6,7,8)$ \\
9 & The following represent intermittent values & $(9,9,9)$ \\
& & \\
& between two adjacent scales & $(1,2,3)$ \\
8 & & $(3,4,5)$ \\
6 & & $(5,6,7)$ \\
& & $(7,8,9)$ \\
\hline
\end{tabular}


Table 3. Criteria preference vector.

\begin{tabular}{|c|c|c|c|}
\hline Criteria & & & \\
\hline NPV & 0.61 & 0.74 & 0.88 \\
\hline IRR & 0.30 & 0.37 & 0.46 \\
\hline ERR & 1.34 & 1.50 & 1.65 \\
\hline PC & 0.34 & 0.39 & 0.46 \\
\hline Env & 1.07 & 1.14 & 1.19 \\
\hline Emp & 1.19 & 1.36 & 1.57 \\
\hline Elig & 1.23 & 1.40 & 1.65 \\
\hline Tech fit & 1.19 & 1.33 & 1.49 \\
\hline Total & 7.27 & 8.21 & 9.34 \\
\hline Total $^{-1}$ & 0.14 & 0.12 & 0.11 \\
\hline $\begin{array}{l}\text { Increasing } \\
\text { order }\end{array}$ & 0.11 & 0.12 & 0.14 \\
\hline
\end{tabular}

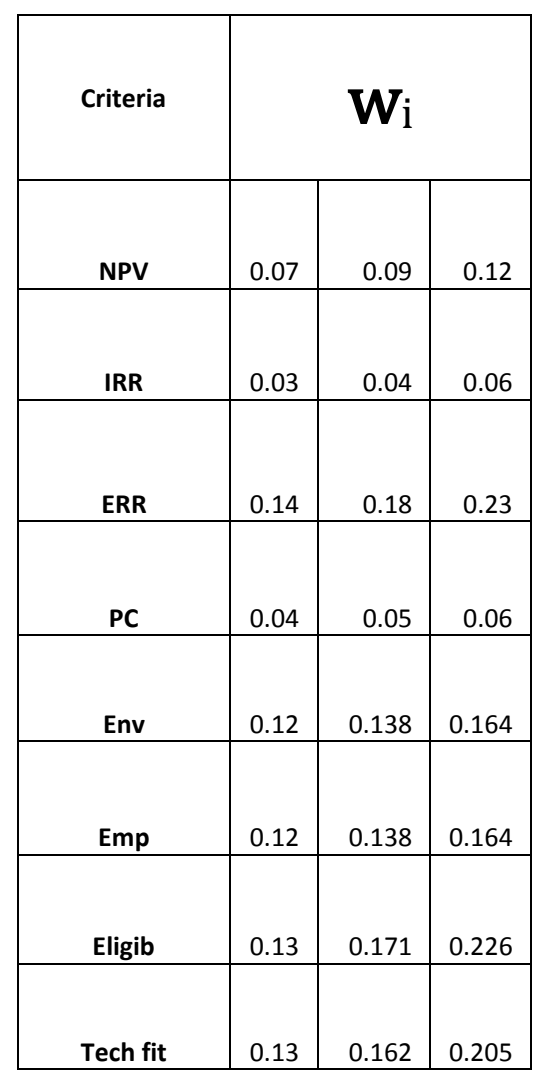

\begin{tabular}{|c|c|c|c|c|}
\hline F-AHP Criteria & Mi & $\mathrm{Ni}$ & $\%$ & Rank \\
\hline NPV & 0.09 & 0.09 & $9 \%$ & 6 \\
\hline IRR & 0.05 & 0.05 & $5 \%$ & 8 \\
\hline ERR & 0.18 & 0.19 & $19 \%$ & 1 \\
\hline PC & 0.05 & 0.05 & $5 \%$ & 7 \\
\hline Env & 0.14 & 0.14 & $14 \%$ & 4 \\
\hline Emp & 0.14 & 0.14 & $14 \%$ & 4 \\
\hline Eligib & 0.18 & 0.18 & $18 \%$ & 2 \\
\hline Tech fit & 0.16 & 0.17 & $17 \%$ & 3 \\
\hline
\end{tabular}


Table 4. Financial criteria.

\begin{tabular}{|l|r|r|r|r|}
\hline Numerical Inputs for the Alternatives & NPV (EUR million) & IRR \% & ERR \% & PC (EUR million) \\
\hline New Builds & 1000 & 12 & 15 & 345 \\
\hline Vessel Lengthening & 600 & 10 & 10 & 150 \\
\hline Second Hand Vessel Acquisition & 800 & 11 & 8 & 175 \\
\hline
\end{tabular}


Table 5. Non-financial criteria.

\section{Alt $1 \quad$ Alt $2 \quad$ Alt 3}

$\begin{array}{llll}\text { Environment } & 25 & 20 & 8\end{array}$

\% Reductions in emissions of NOx, SOx and Particulates

Employment $\quad 6000 \quad 3000 \quad 1000$

During Construction and during operation (figures in man-years)

$\begin{array}{lllll}\text { Technical fit } & 8 & 7 & 6\end{array}$

(estimated by the appraisal team from the range of 1-10 and based on the COP target and eligibility of the project)

$\begin{array}{llll}\text { Eligibility } & \mathbf{7} & \mathbf{7} & \mathbf{5}\end{array}$

(value added contribution to the Bank's involvement in the project and based on a 1-10 evaluation of the fit) 
Table 6. The alternatives' performance decision matrix.

\begin{tabular}{|l|c|r|r|r|r|r|r|r|}
\hline Alternatives - Decision Matrix & \multicolumn{1}{|c|}{ NPV } & \multicolumn{1}{c|}{ IRR } & \multicolumn{1}{c|}{ ERR } & \multicolumn{1}{c|}{$\begin{array}{c}\text { Project } \\
\text { Costs }\end{array}$} & \multicolumn{1}{c|}{ Environment } & Employment & Eligibility & Technical fit \\
\hline New Builds & 0.42 & 0.36 & 0.45 & 0.51 & 0.47 & 0.60 & 0.37 & 0.38 \\
\hline Vessel Lengthening & 0.25 & 0.30 & 0.30 & 0.22 & 0.38 & 0.30 & 0.37 & 0.33 \\
\hline Second Hand Vessel Acquisition & 0.33 & 0.33 & 0.24 & 0.26 & 0.15 & 0.10 & 0.26 & 0.29 \\
\hline
\end{tabular}


Table 7. Final calculated ranking.

\begin{tabular}{|l|c|c|c|r|r|r|r|r|r|}
\hline & NPV & IRR & ERR & Project Costs & Environment & Employment & Eligibility & Technical fit & TOTAL \\
\hline Rank \\
\hline Vew Builds & 0.039 & 0.017 & 0.085 & 0.025 & 0.066 & 0.084 & 0.066 & 0.063 & 0.445 \\
\hline Sessel Lengthening & 0.023 & 0.014 & 0.056 & 0.011 & 0.053 & 0.042 & 0.066 & 0.055 & 0.321 \\
\hline Second Hand Vessel Acquisition & 0.031 & 0.016 & 0.045 & 0.013 & 0.021 & 0.014 & 0.047 & 0.047 & 0.234 \\
\hline
\end{tabular}


Figure legends

Figure 1. Fuzzy triangular numbers.

Figure 2. Project eligibilities.

Figure 3. The proposed F-AHP maritime investment model.

Figure 4. Commercial fleet renewal 'questionnaire'. 
Figures

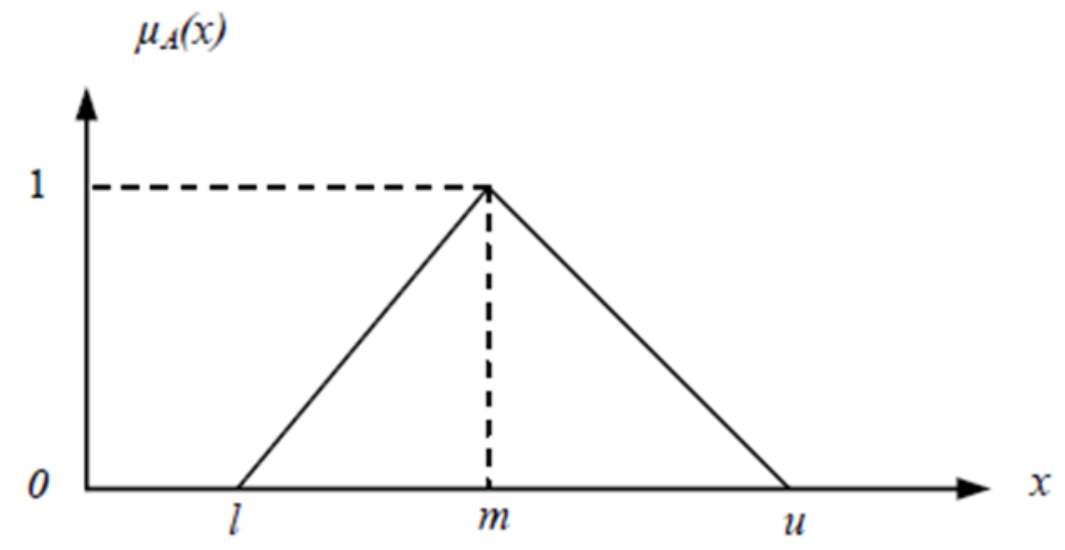

Figure 1 


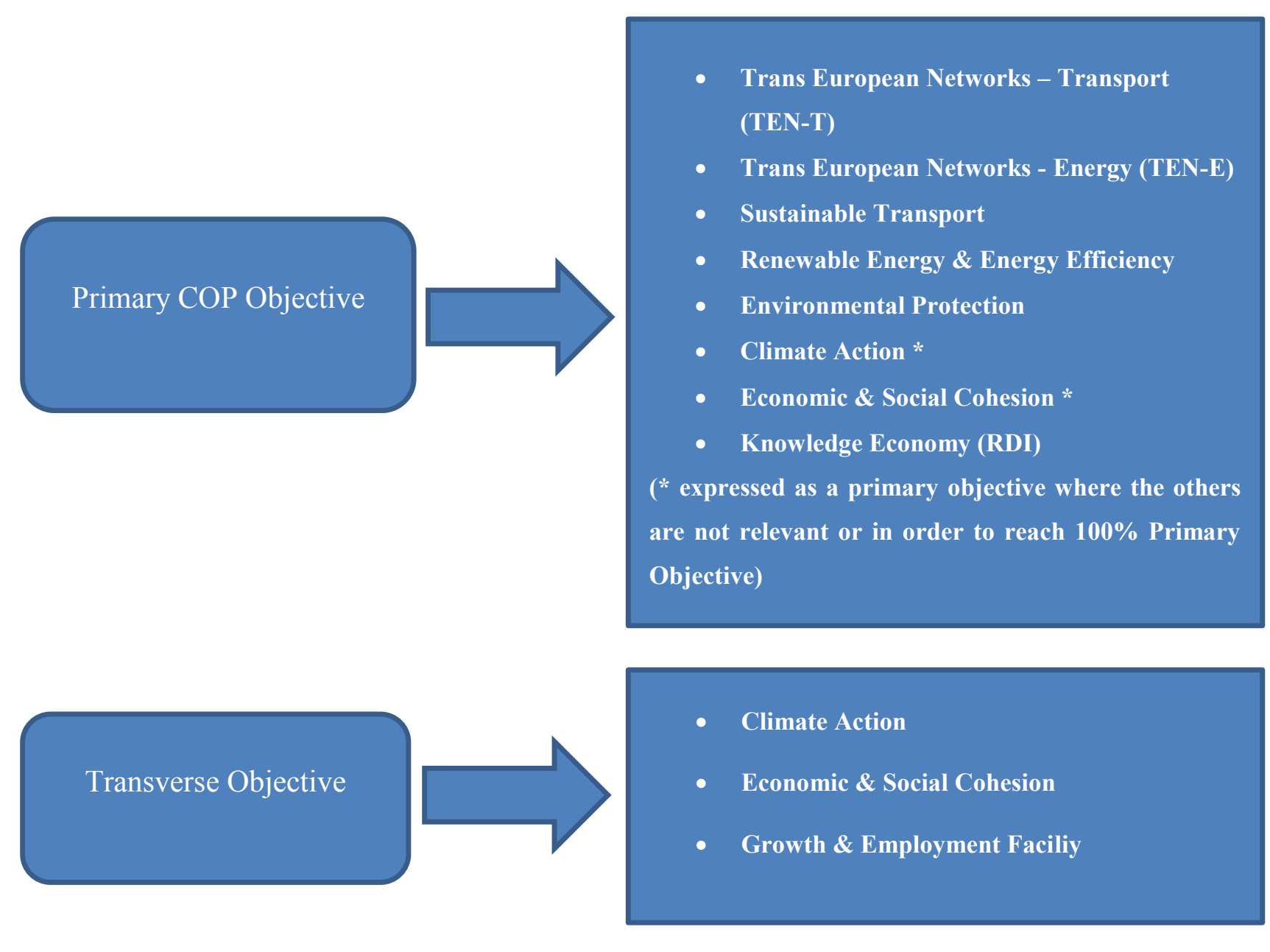

Figure 2 


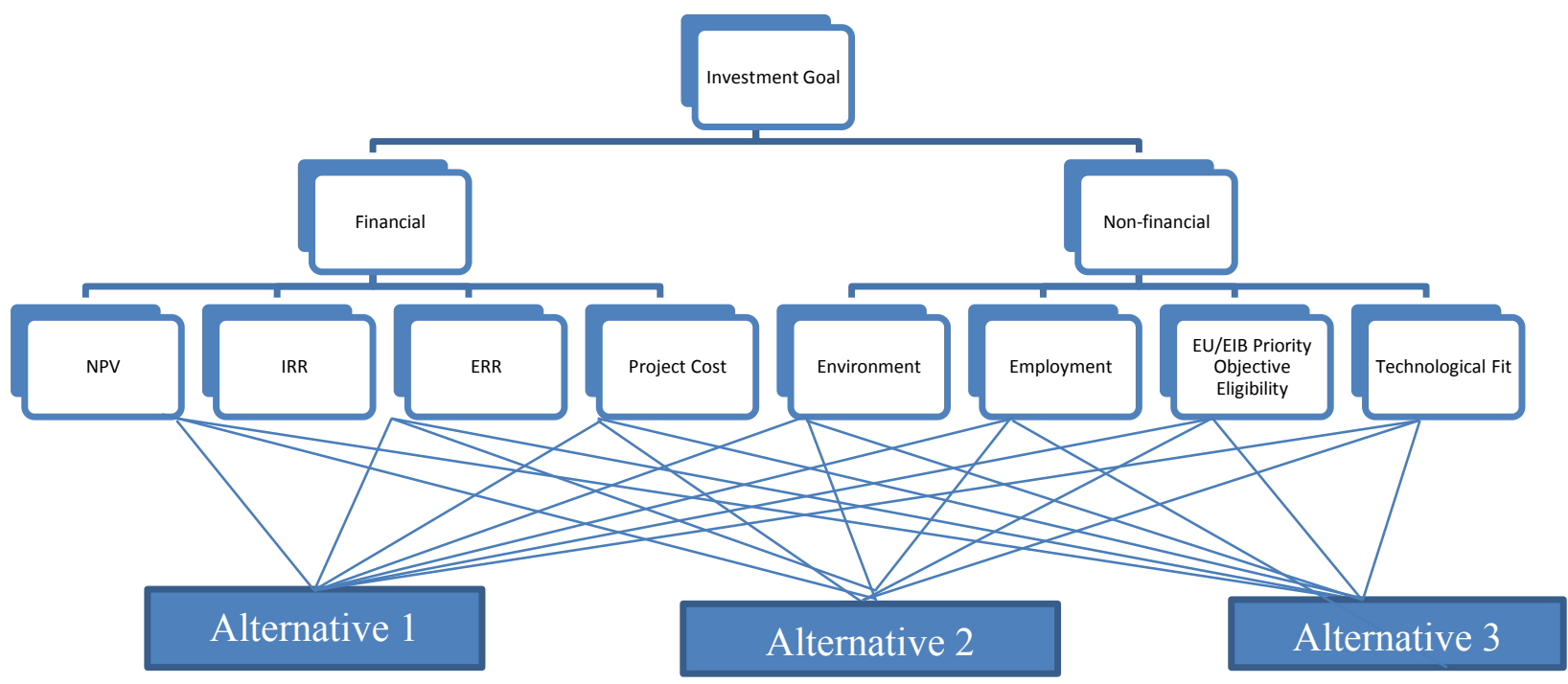

Figure 3 


\begin{tabular}{|c|c|c|c|c|c|c|c|c|c|}
\hline S. Imp & F. Imp & W. Imp & CRITERION & Eq. Imp & CRITERION & W. Imp & F. Imp & S. Imp & A. Imp \\
\hline$(6,7,8)$ & $(4,5,6)$ & $(2,3,4)$ & & $(1,1,1)$ & & $(2,3,4)$ & $(4,5,6)$ & $(6,7,8)$ & $(9,9,9)$ \\
\hline 0 & $\odot$ & 0 & & 0 & & 0 & 0 & 0 & 0 \\
\hline 0 & 0 & 0 & & 0 & & 0 & ○ & 0 & 0 \\
\hline 0 & $\odot$ & 0 & & 0 & & 0 & 0 & 0 & 0 \\
\hline 0 & 0 & 0 & & 0 & & 0 & $\odot$ & 0 & 0 \\
\hline 0 & 0 & $\odot$ & & 0 & & 0 & 0 & 0 & 0 \\
\hline 0 & 0 & 0 & & 0 & & 0 & $\odot$ & 0 & O \\
\hline 0 & 0 & 0 & & 0 & & 0 & 0 & $\odot$ & 0 \\
\hline 0 & 0 & 0 & & 0 & & 0 & $\circ$ & 0 & 0 \\
\hline 0 & 0 & $\odot$ & & 0 & & 0 & 0 & 0 & 0 \\
\hline 0 & 0 & 0 & & 0 & & 0 & $\circ$ & 0 & 0 \\
\hline 0 & 0 & 0 & & 0 & & O & $\circ$ & 0 & 0 \\
\hline 0 & O & 0 & & 0 & & $\odot$ & 0 & 0 & 0 \\
\hline 0 & 0 & 0 & & 0 & & 0 & $\odot$ & 0 & 0 \\
\hline 0 & $\odot$ & 0 & & 0 & & 0 & 0 & 0 & 0 \\
\hline 0 & 0 & 0 & & $\odot$ & & 0 & 0 & 0 & 0 \\
\hline 0 & 0 & 0 & & 0 & & 0 & $\odot$ & 0 & 0 \\
\hline 0 & 0 & 0 & & $\odot$ & & 0 & 0 & 0 & 0 \\
\hline 0 & 0 & 0 & & $\odot$ & & 0 & 0 & 0 & 0 \\
\hline 0 & 0 & 0 & & 0 & & 0 & 0 & 0 & 0 \\
\hline 0 & 0 & 0 & & 0 & & 0 & O & $\circ$ & 0 \\
\hline 0 & O & 0 & & 0 & & 0 & $\odot$ & 0 & O \\
\hline 0 & 0 & 0 & & O & & 0 & 0 & $\circ$ & 0 \\
\hline 0 & 0 & 0 & & $\odot$ & & 0 & 0 & 0 & 0 \\
\hline 0 & 0 & 0 & & $\odot$ & & 0 & O & 0 & O \\
\hline 0 & 0 & 0 & & $\odot$ & & 0 & 0 & 0 & 0 \\
\hline 0 & 0 & 0 & & $\odot$ & & 0 & 0 & 0 & 0 \\
\hline 0 & 0 & 0 & & 0 & & 0 & $\odot$ & 0 & 0 \\
\hline 0 & O & 0 & & 0 & & 0 & $\odot$ & 0 & O \\
\hline
\end{tabular}

Figure 4 